\title{
Abuse and dependence potential of sphingosine-1-phosphate (S1P) receptor modulators used in the treatment of multiple sclerosis: a review of literature and public data
}

\author{
Kerri A. Schoedel ${ }^{1} \cdot$ Carine Kolly $^{2} \cdot$ Anne Gardin $^{2} \cdot$ Srikanth Neelakantham ${ }^{3} \cdot$ Kasra Shakeri-Nejad $^{2}$
}

Received: 6 January 2021 / Accepted: 18 October 2021 / Published online: 13 November 2021

(c) The Author(s) 2021

\begin{abstract}
Abuse and misuse of prescription drugs remains an ongoing concern in the USA and worldwide; thus, all centrally active new drugs must be assessed for abuse and dependence potential. Sphingosine-1-phosphate (S1P) receptor modulators are used primarily in the treatment of multiple sclerosis. Among the new S1P receptor modulators, siponimod, ozanimod, and ponesimod have recently been approved in the USA, European Union (EU), and other countries. This review of literature and other public data has been undertaken to assess the potential for abuse of S1P receptor modulators, including ozanimod, siponimod, ponesimod, and fingolimod, as well as several similar compounds in development. The S1P receptor modulators have not shown chemical or pharmacological similarity to known drugs of abuse; have not shown abuse or dependence potential in animal models for subjective effects, reinforcement, or physical dependence; and do not have adverse event profiles demonstrating effects of interest to individuals who abuse drugs (such as sedative, stimulant, mood-elevating, or hallucinogenic effects). In addition, no reports of actual abuse, misuse, or dependence were identified in the scientific literature for fingolimod, which has been on the market since 2010 (USA) and 2011 (EU). Overall, the data suggest that S1P receptor modulators are not associated with significant potential for abuse or dependence, consistent with their unscheduled status in the USA and internationally.
\end{abstract}

Keywords Abuse $\cdot$ Clinical $\cdot$ Dependence $\cdot$ Fingolimod $\cdot$ Non-clinical $\cdot$ Ozanimod $\cdot$ S1P receptor modulator $\cdot$ Siponimod

\section{Introduction}

Prescription drug misuse and abuse are major public health problems in the USA and other countries. While opioids and tranquilizers (such as benzodiazepines) account for most of the prescription drug abuse, as more opioid products are being re-formulated with abuse-deterrent properties, some individuals who abuse prescription drugs may be switching to other central nervous system (CNS)-activating drugs that are not controlled, such as gabapentin (Evoy et al. 2019). The US Food and Drug Administration (FDA) recently approved

Kerri A. Schoedel

kschoedel@altreos.com

Altreos Research Partners, Inc, Toronto, Canada

2 Novartis Institutes for Biomedical Research, Novartis Pharma AG, Basel, Switzerland

3 Novartis Institutes for Biomedical Research, Novartis Healthcare Pvt Ltd, Hyderabad, India several new centrally active drugs, such as ozanimod and ponesimod, for the treatment of relapsing forms of multiple sclerosis (MS), including clinically isolated syndrome, relapsing-remitting disease, and active secondary progressive disease, in adults (Zeposia Prescribing Information, 2020 and Ponvory Prescribing Information, 2021) earlier, in March 2019, siponimod was approved by the FDA for the same indication (Mayzent Prescribing Information, 2019) and is the first treatment to demonstrate a clinically relevant effect on disability progression in the secondary progressive MS population. Sphingosine-1-phosphate (S1P) receptor modulators induce long-lasting internalization of $\mathrm{S}_{1} \mathrm{P}_{1}$ receptors expressed on the lymphocytes, inhibiting the egress of lymphocytes from lymph nodes, and preventing infiltration of autoreactive lymphocytes into the CNS, thereby reducing neuroinflammation (Gergely et al. 2012). Non-clinical evidence suggests that S1P modulators regulate neuro-inflammatory processes and may promote CNS repair mechanisms and remyelination (Gentile et al. 2016). Ozanimod, ponesimod, and siponimod share pharmacological similarities with another approved 
drug fingolimod as well as other S1P receptor modulators in development (e.g., amiselimod). Other members of this class have also been studied for use in other conditions, including chronic inflammatory demyelinating polyradiculoneuropathy, amyotrophic lateral sclerosis and renal transplants (fingolimod), chronic plaque psoriasis (ponesimod), ulcerative colitis (amiselimod and etrasimod), systemic lupus erythematosus (cenerimod), and other autoimmune diseases, such as Crohn's disease, atopic dermatitis, and alopecia areata.

According to the FDA Guidance, all CNS-active new drugs must be assessed for their abuse and dependence potential (Center for Drug Evaluation and Research (CDER) 2017). However, fingolimod, siponimod, ponesimod, and ozanimod do not have any information in Sect. 9 ("Drug Abuse and Dependence") of their US prescribing information. This is consistent with the recent FDA draft guidance indicating that Sect. 9 applies to drugs that are controlled under the Controlled Substances Act (CSA) or those that are "not controlled under the CSA for which there is important information to convey to health care providers related to abuse and dependence" (Center for Drug Evaluation and Research (CDER) 2019a). The absence of Sect. 9 in the US labels of these drugs suggests that the FDA believes that there is no information to convey regarding the abuse or dependence potential of fingolimod, siponimod, ponesimod, or ozanimod; however, the data contributing to these decisions are not readily available to researchers or health care practitioners.

Therefore, in this article, we reviewed the available data on the abuse and dependence potential of FDA-approved $\mathrm{S} 1 \mathrm{P}$ receptor modulators (including fingolimod, siponimod, ozanimod, and ponesimod) based on published literature and other publicly accessible sources of information (including open access regulatory review documents). This includes examination of what is known about the pharmacology of the class, animal studies on abuse and dependence potential, clinical data including pharmacokinetic factors, pharmacodynamics, and adverse event (AE) profiles that may be associated with abuse as well as a review of literature on any cases of actual abuse, misuse, diversion, dependence, or withdrawal with S1P receptor modulators (primarily fingolimod, as it has been in the market for several years). We believe that this review will help to fill an information gap left by the absence of this information in the US-based prescribing information, as prescription drug abuse is an important topic that needs to be addressed for all CNS-active drugs.

\section{Non-clinical pharmacology and behavioral effects in animals}

Different S1P receptor modulators have slightly different neuropharmacology, with varying selectivity for S1P receptor subtypes. While fingolimod is relatively non-selective and modulates $\mathrm{S}_{1} \mathrm{P}_{1}, \mathrm{~S}_{1} \mathrm{P}_{3}, \mathrm{~S}_{1} \mathrm{P}_{4}$, and $\mathrm{S}_{1} \mathrm{P}_{5}$ receptor subtypes, siponimod, and ozanimod are selective for $\mathrm{S}_{1} \mathrm{P}_{1}$ and $\mathrm{S}_{1} \mathrm{P}_{5}$ receptor subtypes, and ponesimod selectively modulates the $\mathrm{S} 1 \mathrm{P}_{1}$ receptor sub-type (Chaudhry et al. 2017; Sugahara et al. 2017). Less data are available for other S1P receptor modulators that were not yet approved at the time of manuscript review, such as amiselimod, etrasimod, and cenerimod, while some members of this class (ceralifimod and GSK2018682) have been discontinued in development, and since no relevant data were identified for these drugs, they are not discussed further.

A search of Medline, Embase, and Cochrane was performed in February 2020 using the following search parameters with limits for "animals" and "2008 to present," and excluding humans: [Dopamine, Monoamine, Nucleus accumbens, Hypothalamus, Microdialysis, Discrimination, Discriminative, Generalization, Generalize, Self-administration, Reinforce, Reinforcement, Reinforcing, Reward, Rewarding, Conditioned Place Preference, CPP, Conditioned Place Aversion, Intracranial self-stimulation, ICSS, self-stimulation, Dependence, Withdrawal, Discontinuation, Post-treatment OR Rebound] AND [Siponimod, Fingolimod, Ponesimod, Ozanimod OR Sphingosine-1-Phosphate]. No published animal abuse or dependence potential studies with $\mathrm{S} 1 \mathrm{P}$ receptor modulators were identified in the scientific literature. However, some data are available in the FDA review material for siponimod, ozanimod, and ponesimod (Center for Drug Evaluation and Research (CDER), 2019b; Center for Drug Evaluation and Research (CDER), 2020b; Center for Drug Evaluation and Research (CDER) 2021).

Non-clinical studies performed during development of siponimod and ozanimod included in vitro and in vivo studies (Center for Drug Evaluation and Research (CDER), 2019b; Center for Drug Evaluation and Research (CDER), 2020b). For siponimod, the FDA review documents indicate that "siponimod [at $10 \mu \mathrm{M}$ ] binds to receptors (e.g., dopamine, serotonin, and opiate-mu, -delta and -kappa) that are associated with abuse-related effects. However, due to the high levels of plasma-bound siponimod (greater than 99.9\%) it is not expected that significant concentrations of siponimod will reach the brain to activate these receptors... the concentrations of siponimod at the therapeutic dose of $2 \mathrm{mg}$ (and $10 \mathrm{mg}, 5$ times the therapeutic dose are estimated to be present in the cerebrospinal fluid (CSF) (presumed surrogate for brain concentrations) several thousand-fold lower than the receptor binding $\mathrm{IC}_{50}$ values for any of the off-target sites." This indicates that siponimod is selective for S1P receptors and is not expected to have off-target effects known to be associated with abuse at clinically relevant concentrations. Although it is quite reasonable to use the unbound drug concentration in plasma, to predict the unbound drug concentration at the active site in the brain provided that there is no active transporter involved in drug distribution 
(free drug hypothesis) (Lin, 2008), several additional factors may also influence brain exposure, such as protein binding in brain tissue, physicochemical properties, and brain disposition.. The FDA review documents for ozanimod indicate that "Binding assays demonstrate that ozanimod and its metabolite CC1084037 bind to several targets associated with abuse-related effects"; however, these findings were not confirmed in vivo, suggesting that off-target activities are not clinically relevant. According to the FDA review documents, ponesimod "does not bind to abuse-related targets" (Center for Drug Evaluation and Research (CDER) 2021). Although S1P receptor modulators may not directly bind to abuse-related receptors, in vitro studies published in the literature have suggested that exogenously applied S1P appears to modulate glutamatergic pathways, primarily through the regulation of glutamate secretion (Riganti et al. 2016; Sim-Selley et al. 2009), and may also affect the release of gamma-aminobutyric acid (GABA) (Kanno and Nishizaki 2011), both pathways that are associated with abuse (i.e., N-methyl-D-aspartate [NMDA] antagonists such as ketamine and GABAergic drugs such as barbiturates and benzodiazepines). This appears to be mediated primarily by the $\mathrm{S}_{1} \mathrm{P}_{3}$ receptor sub-type (Kanno and Nishizaki 2011; Riganti et al. 2016). However, glutamate levels are higher in the cerebrospinal fluid and brain tissue of MS patients, and NMDA and kainate receptors are upregulated (Newcombe et al. 2008; Srinivasan et al. 2005). Thus, modulation of the central S1P pathways could correct cortical excitability in these patient populations, as indicated by a recent clinical study with fingolimod (Landi et al. 2015), rather than affecting normal glutamatergic activity in healthy individuals.

Three animal studies with siponimod evaluated different aspects of abuse and dependence potential (Center for Drug Evaluation and Research (CDER), 2019b). A drug discrimination study in rats found no subjective similarities ("discriminative stimulus effects") between siponimod and midazolam (a prototypical sedative) and amphetamine (a prototypical stimulant), indicating that siponimod does not have subjective effects similar to these drug classes of abuse. A self-administration study found that rats trained to selfadminister cocaine did not self-administer siponimod at rates higher than the vehicle, demonstrating that siponimod does not have reinforcing effects in animals. Finally, a 28-day chronic dosing rat physical dependence study compared siponimod with vehicle and diazepam as a positive control. In contrast to diazepam, no differences were observed in withdrawal-related behavior and signs in rats who were administered siponimod compared with those administered vehicle. These data indicate that chronic exposure to siponimod does not induce physical dependence in animals. A single animal abuse study was performed with ozanimod and its major active metabolite CC112273. This self-administration study did not demonstrate any reinforcing effect of ozanimod or CC112273 in rats (Center for Drug Evaluation and Research (CDER), 2020b). No animal drug discrimination or physical dependence studies with ozanimod or CC112273 were reported. According to the FDA review material, no dedicated animal abuse potential studies were conducted with ponesimod; however, it was noted that ponesimod "does not induce acute CNS- and discontinuation/withdrawal-related symptoms or behaviors in animals" (Center for Drug Evaluation and Research (CDER) 2021).

While no relevant non-clinical data on other S1P receptor modulators were identified at the time of this review, the non-clinical data outlined in regulatory review documents indicate that there are no signals associated with abuse and dependence potential for this class.

\section{Clinical pharmacology data relevant to abuse}

A search of Medline, Embase, and Cochrane was performed in February 2020 using the following search parameters with limits for "humans" and "2008 to present": [addiction, psychosis, aggression, agitation, amnesia, anxiety, cognitive impairment, balance disorder, confusion, déjà vu, delirium, delusion, disorientation, dizziness, drunk, dysphoria, euphoric, euphoria, hallucination, illusion, memory, panic attack, paranoia, psychotic, sedation, somnolence, liking OR subjective] AND [siponimod, fingolimod, ponesimod, ozanimod OR Sphingosine 1-Phosphate]. The articles retrieved from these searches were also evaluated for AEs potentially associated with abuse as described in the next section.

No human abuse potential studies in recreational drug users or other clinical studies of subjective/abuse-related effects were identified for any S1P receptor modulator. The FDA review documents for siponimod, ponesimod, and ozanimod indicate that human abuse potential studies were not considered necessary based on the non-clinical and clinical AE data (Center for Drug Evaluation and Research (CDER), 2019b; Center for Drug Evaluation and Research (CDER), 2020b; Center for Drug Evaluation and Research (CDER) 2021). However, clinical data are available for pharmacokinetic factors, which may have an impact on the abuse potential of drugs of abuse, such as opioids or stimulants, for which the more rapid onset and elimination are known to be associated with a greater "high" and abuse potential. Table 1 summarizes available pharmacokinetic data for the active moieties of S1P modulators (i.e., parent [if active] and active metabolites). Note that fingolimod has no pharmacological activity and undergoes phosphorylation to produce fingolimod-phosphate (fingolimod-P), the active moiety. As shown in Table 1, most S1P receptor modulators have a moderately slow or very slow onset (time to maximum plasma concentrations of 2.5 to $4 \mathrm{~h}$ for siponimod and 
Table 1 Summary of pharmacokinetic parameters of S1P receptor modulators (active moieties)

\begin{tabular}{|c|c|c|c|c|c|}
\hline Drug/active metabolite(s) & $\begin{array}{l}\text { Median } \mathrm{T}_{\max } \text { or } \\
\mathrm{T}_{\text {max,ss }} \text { (hours) }\end{array}$ & $\begin{array}{l}\text { Absolute bio- } \\
\text { availability (\%) }\end{array}$ & Mean $\mathrm{T}_{1 / 2}$ (hours) & $\mathrm{fu}(\%)$ & References \\
\hline Fingolimod-P (active) $)^{\mathrm{a}}$ & 6 & NA & 168 & 0.3 & David et al. 2012; CDER 2010a \\
\hline Siponimod & $3-4$ & 84 & $22-36$ & $0.017-0.055$ & $\begin{array}{l}\text { Gergely et al. 2012; CDER } \\
\text { 2019b; Gardin et al. } 2017\end{array}$ \\
\hline Ozanimod & $6-8$ & - & 20 & 1.8 & CDER 2020a; Tran et al. 2020 \\
\hline CC112273 (major active moiety) & $6-10$ & NA & 280 & 0.2 & \\
\hline CC1084037 & 16 & NA & 280 & 0.7 & \\
\hline Ponesimod & $2-4$ & 83.8 & 33 & 0.4 & CDER 2020c \\
\hline
\end{tabular}

${ }^{a}$ Fingolimod has no pharmacological activity and undergoes phosphorylation to produce fingolimod-P, the active moiety

fu unbound fraction; NA not applicable; S1P sphingosine-1-phosphate; $T_{\max }$ time to maximum plasma concentration; $T_{\max , \mathrm{ss}}$ time to maximum plasma concentration at steady-state; $T_{1 / 2}$ elimination half-life

ponesimod and 6 to $21 \mathrm{~h}$ for fingolimod-P and ozanimod/ CC112273 [the combination of which is thought to be the active moiety of ozanimod]) and moderately long or very long elimination half-lives ( 17 to $36 \mathrm{~h}$ for siponimod, ozanimod, and ponesimod and $\geq 168 \mathrm{~h}$ for fingolimod-P and the major active metabolite of ozanimod [CC112273]), which may partly contribute to the lack of abuse-related subjective effects for this class (as described in the next section). In addition, in available data (fingolimod, ponesimod, and siponimod), the unbound fractions of drug (free circulating drug) are fairly low (due to high plasma protein binding), which may contribute to receptor selectively for S1P and lack of off-target effects on abuse-related molecular targets as described in the previous section (Boehler et al. 2017; David et al. 2012; Gardin et al. 2017; Gergely et al. 2012; Glaenzel et al. 2018; Guerard et al. 2016; Hoch et al. 2014; Rasche and Paul 2018; Shakeri-Nejad et al. 2015; Tran et al. 2018; Center for Drug Evaluation and Research (CDER) 2010a, 2019b, 2020a, b).

\section{Clinical AE data suggestive of abuse or dependence potential}

According to the FDA Guidance (Center for Drug Evaluation and Research (CDER), 2017), CNS AEs that are potentially "abuse-related" should be systematically evaluated. These AEs may signal subjective effects of interest to individuals who abuse drugs, such as mood-elevating (e.g., "euphoric mood"), hallucinogenic, sedative (e.g., "somnolence" or "sedation"), or stimulant (e.g., "psychomotor hyperactivity") effects (Mansbach et al. 2010; Sellers and Romach 2018).

\section{Clinical trial data from the scientific literature}

Published clinical trials were reviewed to extract psychiatric system or nervous system disorders potentially associated with abuse (according to the FDA Guidance; Center for
Drug Evaluation and Research (CDER), 2017). Although there are numerous additional trials with $\mathrm{S} 1 \mathrm{P}$ receptor modulators, particularly for fingolimod, many articles did not report the AEs of interest for this review and therefore have not been cited. Data are presented as proportion of subjects reporting the $\mathrm{AE}$ (percent incidence) with active drug along with placebo-corrected incidence (shown as percent incidence with active drug - percent incidence with placebo) where placebo data were available. Ranges of data (i.e., X\% to $\mathrm{X} \%$ ) represent percent incidence (and placebo-corrected percent incidence) reported across individual studies; no pooling was performed. A review of published clinical trials of S1P receptor modulators demonstrated that the most common potentially CNS-related AEs associated with this class are dizziness and fatigue/tiredness, with a lower incidence of other AEs of interest, such as somnolence (indicating sedative effects), anxiety, or depression (Table2). Only 1 trial reported other events of interest ("euphoric mood" for ponesimod). Although dizziness is listed as a "euphoriarelated" term of interest in the FDA Guidance (Center for Drug Evaluation and Research (CDER), 2017), in this case it may be related to the well-known transient bradyarrhythmic and heart-rate decreasing effects of this class (Urbano et al. 2013) rather than being a direct CNS effect that may indicate euphoria. As shown in Table 2, although the incidence of dizziness was higher with ponesimod compared with the other members of the class, it may simply be an artifact of the larger number of healthy subject trials published for this drug (which tend to have small sample sizes that skew incidence data and are often open-label) and the more complete AE data provided in the articles. Indeed, the incidence of dizziness is more similar for trials in relapsing-remitting MS (RRMS) patients. Some AEs that potentially indicate centrally mediated effects, such as depression and anxiety, have also been reported; however, MS patients frequently present with anxiety and depression, i.e., these have been reported in over $20 \%$ of MS patients (Marrie et al. 2015). In several studies and 1 meta-analysis, fingolimod and other 
Table 2 Summary of CNS adverse events of potential interest in published clinical trials

\begin{tabular}{|c|c|c|c|c|c|c|c|}
\hline \multirow{3}{*}{$\begin{array}{l}\text { Adverse event } \\
\text { term }\end{array}$} & \multicolumn{7}{|c|}{ Percentage of subjects/patients [percent incidence for active - percent incidence for placebo] ${ }^{\mathrm{a}}$} \\
\hline & \multirow{2}{*}{$\begin{array}{l}\text { Fingolimod } 0.5 \text {, } \\
1.25 \text {, and } 5 \mathrm{mg}^{\mathrm{b}} \\
\text { Patients with } \\
\text { MS }\end{array}$} & \multicolumn{2}{|c|}{ Ponesimod 10 to $100 \mathrm{mg}^{\mathrm{c}}$} & \multicolumn{2}{|c|}{ Siponimod 2 and $10 \mathrm{mg}^{\mathrm{d}}$} & \multicolumn{2}{|c|}{ Ozanimod 0.25 to $3 \mathrm{mg}^{\mathrm{e}}$} \\
\hline & & $\begin{array}{l}\text { Patients with } \\
\text { MS }\end{array}$ & Healthy subjects & $\begin{array}{l}\text { Patients with } \\
\text { MS }\end{array}$ & Healthy subjects & $\begin{array}{l}\text { Patients with } \\
\text { MS }\end{array}$ & Healthy subjects \\
\hline Dizziness & $\begin{array}{l}0.1 \text { to } 13 \% \\
{[-3 \text { to }+5.2 \%]}\end{array}$ & $\begin{array}{l}4.5 \text { to } 9.2 \% \\
{[+3.0} \\
\text { to }+6.7 \%]\end{array}$ & $\begin{array}{l}0 \text { to } 64.3 \% \\
{[0 \text { to }+25 \%]}\end{array}$ & $7 \%[+2 \%]$ & 5.3 to $12.5 \%$ & $\mathrm{~N} / \mathrm{R}$ & $7.4 \%[+3.2 \%]$ \\
\hline $\begin{array}{l}\text { Fatigue/tired- } \\
\text { ness }\end{array}$ & $\begin{array}{l}6.5 \text { to } 33 \% \\
{[-8 \text { to }+0.5 \%]}\end{array}$ & $\begin{array}{l}5.0 \text { to } 7.9 \% \\
{[-0.8} \\
\text { to }+2.1 \%]\end{array}$ & $\begin{array}{l}4.2 \text { to } 50 \% \\
{[-27.1 \text { to }+3.2]}\end{array}$ & $\mathrm{N} / \mathrm{R}$ & $6.3 \%$ & $\mathrm{~N} / \mathrm{R}$ & $5.9 \%[+1.7 \%]$ \\
\hline Anxiety & $3.6 \%[0 \%]$ & $\mathrm{N} / \mathrm{R}$ & $\mathrm{N} / \mathrm{R}$ & $\mathrm{N} / \mathrm{R}$ & $6.7 \%$ & $\begin{array}{l}2.3-2.4 \% \\
{[+2.3} \\
\quad \text { to }+2.4 \%]\end{array}$ & $\mathrm{N} / \mathrm{R}$ \\
\hline Depression & $\begin{array}{l}2.9 \text { to } 10 \% \\
{[-2.0 \text { to }+1.1]}\end{array}$ & $\mathrm{N} / \mathrm{R}$ & $\mathrm{N} / \mathrm{R}$ & N/R & & $\begin{array}{l}1.2-3.4 \% \\
{[+0.1} \\
\quad \text { to }+2.3 \%]\end{array}$ & $\mathrm{N} / \mathrm{R}$ \\
\hline Somnolence & $0.2 \%$ & $\mathrm{~N} / \mathrm{R}$ & $15.5 \%[+3.2 \%]$ & N/R & & NR & $8.8 \%[+4.6 \%]$ \\
\hline Euphoric mood & $N / R$ & $N / R$ & $8.6 \%[+8.6 \%]$ & N/R & & $N / R$ & \\
\hline
\end{tabular}

Includes psychiatric system or nervous system disorders. Note that not all articles included coded (MedDRA) terms, so alternative terms (such as tiredness) are also reported. Unless otherwise specified, data are for patient trials, primarily in RRMS

Note that although there are numerous additional trials with S1P receptor modulators, particularly fingolimod, many did not report adverse events of interest for this review and therefore have not been cited

${ }^{a}$ Data are presented as percent incidence with active drug (percent incidence for active-percent incidence for placebo) where placebo data were available. Ranges of data (i.e., X\% to X\%) represent incidence (placebo-corrected incidence) reported across individual studies. No pooling was performed

${ }^{\mathrm{b}}$ Includes patients with MS, chronic inflammatory demyelinating polyradiculoneuropathy, amytrophic lateral sclerosis, and renal transplant (Berry et al. 2017; Budde et al. 2002; Calabresi et al. 2014; Hughes et al. 2018; Kappos et al. 2006; Kappos et al. 2010; Khatri et al. 2011; Laroni et al. 2014; Lublin et al. 2016; Montalban et al. 2015; Ordonez-Boschetti et al. 2015; Rojas et al. 2017; Saida et al. 2012)

${ }^{c}$ Patients with MS and chronic plaque psoriasis and healthy volunteers (Boehler et al. 2017; Hoch et al. 2014, 2015; Juif et al. 2015, 2017; Brossard et al. 2014; Olsson et al. 2014; Scherz et al. 2015; Vaclavkova et al. 2014)

${ }^{\mathrm{d}}$ Patients with MS and healthy volunteers (Glaenzel et al. 2018; Al-Salama 2019; Biswal et al. 2015; Gardin et al. 2018)

${ }^{\text {e}}$ Patients with MS and healthy volunteers (Cohen et al. 2016; Tran et al. 2018)

$C N S$ central nervous system, MedDRA Medical Dictionary for Regulatory Activities; $M S$ multiple sclerosis; $N / R$ not reported; RRMS relapsing remitting multiple sclerosis; $S 1 P$ sphingosine-1-phosphate

disease-modifying therapies (DMTs) for MS had no significant association with the onset of anxiety, depression, or other neuropsychiatric events (Al-Hussain et al. 2017; Gasim et al. 2018; Moreau et al. 2017; Tauil et al. 2018). In a subset of 141 African-American RRMS patients from a randomized open-label study, fingolimod $(0.5 \mathrm{mg} /$ day $)$ was associated with a lower AE rate (AEs per patient-year) compared with injectable DMTs for anxiety (0.055 vs. 0.161$)$ and depression (0.092 vs. 0.134) (Cascione et al. 2018). Higher rates of dizziness (0.091 vs. 0.066 ) and fatigue (0.114 vs. 0.065 ) were observed with fingolimod vs. injectable DMTs in this study and in another open-label study of RRMS patients (reported as percent incidence: $6.4 \%$ vs. $2.9 \%$ for dizziness and $11.5 \%$ vs. $5.7 \%$ for fatigue; Fox et al. 2014), although in many trials, the incidence of fatigue is similar or lower with fingolimod compared with placebo (Table2) (Al-Salama
2019; Berry et al. 2017; Biswal et al. 2015; Boehler et al. 2017; Brossard et al. 2014; Budde et al. 2002; Calabresi et al. 2014; Cohen et al. 2016; Gardin et al. 2018; Glaenzel et al. 2018; Hoch et al. 2014; Hoch et al. 2015; Hughes et al. 2018; Juif et al. 2015; Juif et al. 2017; Kappos et al. 2006; Kappos et al. 2018a; Kappos et al. 2010; Khatri et al. 2011; Laroni et al. 2014; Lublin et al. 2016; Montalban et al. 2015; Olsson et al. 2014; Ordonez-Boschetti et al. 2015; Rojas et al. 2017; Saida et al. 2012; Scherz et al. 2015; Tran et al. 2018; Vaclavkova et al. 2014).

\section{Clinical trial data from FDA review documents}

More detailed data for CNS AEs of interest in a 12-month safety population were obtained from the fingolimod FDA review documents and are summarized in Table 3. In a 
pooled data set of MS patients with 12 months of exposure, the most common of these AEs with $0.5 \mathrm{mg}$ fingolimod (shown as fingolimod - placebo) was depression $(+1.2 \%$ greater than placebo); however, the incidence of this event with the $1.25 \mathrm{mg}$ dose was not greater than that with placebo. With the $1.25 \mathrm{mg}$ fingolimod dose, dizziness and insomnia were the most common CNS AEs that occurred with a higher incidence vs. placebo $(+1.8 \%$ and $+1.7 \%$, respectively). In healthy subjects, dizziness occurred more frequently with fingolimod compared with placebo (incidence of $7.0 \%$ vs. $3.1 \%$ subjects with placebo; difference

Table 3 Placebo-corrected incidence of CNS adverse events of potential interest with fingolimod in pooled MS patients with 12 months of exposure from review documents

\begin{tabular}{|c|c|c|}
\hline \multirow{4}{*}{ Adverse event term } & \multicolumn{2}{|c|}{ PR of fingolimod - PR of placebo } \\
\hline & Fingolimod $0.5 \mathrm{mg}$ & Fingolimod $1.25 \mathrm{mg}$ \\
\hline & $N=854$ & $N=849$ \\
\hline & $N y=793.2$ & $N y=746.8$ \\
\hline Dizziness & 0.8 & 1.7 \\
\hline Emotional disorder & 0 & 0.3 \\
\hline Abnormal behavior & 0 & 0.1 \\
\hline Feeling drunk & 0 & 0.1 \\
\hline Euphoric mood & 0 & 0.1 \\
\hline Mood swings & 0.5 & 0.1 \\
\hline Restlessness & 0.1 & 0.1 \\
\hline ADHD & 0 & 0.1 \\
\hline Depersonalization & 0 & 0.1 \\
\hline Emotional distress & 0 & 0.1 \\
\hline Impatience & 0 & 0.1 \\
\hline Mental disorder & 0 & 0.1 \\
\hline Mood altered & 0.6 & 0.1 \\
\hline Aggression & 0.1 & 0.1 \\
\hline Derealization & 0 & 0.1 \\
\hline Agitation & 0.3 & 0 \\
\hline Depression & 1.2 & 0 \\
\hline Irritability & 0.6 & 0 \\
\hline Confusional state & 0.1 & -0.2 \\
\hline Speech disorder & 0.1 & -0.2 \\
\hline Cognitive disorder & 0.1 & -0.3 \\
\hline Insomnia & -0.3 & -0.4 \\
\hline
\end{tabular}

Modified from FDA CDER Application Number 22-527 Other Review(s)-Table 4, 2010 (CDER, 2010b) containing pooled data in MS patients with the drug exposure of 12 months

The values presented in this table are the PR with fingolimod minus the PR with placebo. $P R=100$ patient-year rate calculated as $\mathrm{n} /$ Ny*100

$A D H D$ attention-deficit hyperactive disorder; $C N S$ central nervous system; FDA Food and Drug Administration; $M S$ multiple sclerosis; $n$ number of abuse-related adverse events that occurred to all patients; $N y$ patient-year defined as the sum of the number of days on study drug for all patients in each treatment group divided by 365.25 of $+3.9 \%$; CDER, 2010b). Somnolence had a slightly higher incidence in fingolimod-treated subjects compared with placebo-treated subjects $(0.7 \%$ vs. $0.3 \% ;+0.4 \%)$, while differences between fingolimod- and placebo-treated subjects were even smaller for other AEs of interest $(\leq 0.2 \%$ difference).

The FDA review documents for ozanimod indicate that "abuse-related AEs in this population [healthy subjects] were infrequent and included AEs such as somnolence, insomnia, abnormal dreams, euphoria, fatigue, decreased appetite, anxiety and energy increased and sleep abnormalities." In a pooled data set of MS patients treated with ozanimod in phase 2 and 3 studies, the most common of these events was somnolence, occurring in $1.6 \%$ of subjects, while the other AEs occurred in $\leq 1 \%$ of subjects. In RRMS patients, the most common CNS AEs that had a higher incidence than placebo were anxiety $(+1.6 \%)$, depression $(+1.4 \%)$, asthenia $(+1.3 \%)$, and fatigue $(+1.1 \%)$. The incidence of the remaining CNS AEs was $\leq 0.5 \%$ higher vs. placebo (Table4).

A consolidated summary table of AEs was not available in the FDA review documents for ponesimod; however, data were presented by individual study. AE data from the double-blind portion of the phase 3 study in MS patients is presented in Table 5 (Center for Drug Evaluation and Research (CDER), 2021). Depression, anxiety, and somnolence were the most commonly reported CNS AEs of potential interest; however, the incidence of these types of events was similar vs. the unscheduled immunomodulator teriflunomide, with the exception of somnolence, which had a slightly higher incidence (3.2\% vs. 1.6\%). One subject also reported "drug withdrawal syndrome" in the ponesimod group; however, it is unclear if this was related to ponesimod or another substance, as FDA review documents indicate that "withdrawal symptoms, which may indicate physical dependence, did not occur upon discontinuation of ponesimod." In Phase 1 studies, review document note "the occurrence of euphoric mood in four Phase 1 studies may indicate that ponesimod has abuse potential.... The occurrence of euphoric mood at supratherapeutic doses (40 mg, $75 \mathrm{mg}$ ) of ponesimod in some studies is further suggestive of abuse potential." These events led the FDA to recommend further post-market monitoring for the abuse potential of ponesimod.

A full table of siponimod-related CNS AEs was also not provided in the FDA review documents (CDER 2019). However, some information is provided for 8 of $1333 \mathrm{MS}$ patients $(0.6 \%)$ who reported potentially abuse-related AEs, including feeling abnormal, derealization, hallucinations, and euphoric mood in 2 patients $(0.15 \%)$ each and feeling drunk and feeling abnormal in 1 patient $(0.8 \%)$ each. Most of these events were not considered by the investigators to be related to the study drug, although the assessment was not provided for a few events (feeling abnormal, derealization, 
Table 4 Placebo-corrected incidence of CNS adverse events of potential interest with ozanimod in MS patients from pooled phase 2 and 3 studies from review documents

\begin{tabular}{lc}
\hline Adverse event term & $\begin{array}{l}\text { Percent incidence with ozanimod - } \\
\text { percent incidence with placebo } \\
\text { Ozanimod all doses }(0.5 \text { and } 1 \mathrm{mg}) \\
N=1944\end{array}$ \\
\hline Anxiety & 1.6 \\
Depression & 1.4 \\
Asthenia & 1.3 \\
Fatigue & 1.1 \\
Depressed mood & 0.5 \\
Anxiety disorder & 0.4 \\
Decreased appetite & 0.4 \\
Sleep disorder & 0.2 \\
Dyssomnia & 0.2 \\
Increased appetite & 0.2 \\
Memory impairments & 0.2 \\
Panic disorder & 0.1 \\
Affective disorder & 0.05 \\
Hallucinations & 0.05 \\
Mental disorder & 0.05 \\
Suicidal ideation & 0.05 \\
Suicide attempt & 0.05 \\
Somnolence & -0.5 \\
Disturbance in attention & -0.9 \\
Irritability & -0.9 \\
Insomnia & -2.1 \\
\hline
\end{tabular}

Modified from CDER 2020b

The values presented in this table are the percentage of subjects with adverse events (percent incidence) with ozanimod minus the percent incidence of adverse events with placebo

CNS central nervous system; FDA Food and Drug Administration; $M S$ multiple sclerosis

and feeling drunk). In addition, the review document states that because these events were not seen in healthy subjects, it seems unlikely that siponimod caused these AEs in the MS patients.

Overall, clinical trial AE data from scientific literature and FDA review documents indicate that $\mathrm{S} 1 \mathrm{P}$ receptor modulators do not appear, as a whole, to be associated with subjective or neuropsychiatric effects that may be of interest to individuals who abuse drugs.

\section{Post-market reports of actual abuse, misuse, dependence, or withdrawal}

A review of literature was performed to identify any potential reports of fingolimod abuse, misuse, diversion, dependence, or withdrawal. PubMed searches were performed in
February 2020 with the search term [fingolimod] AND [abuse, misuse, dependence, addict, addiction, diversion, withdrawal, overdose, intoxication, OR poisoning]. The searches were also performed for siponimod; however, due to a relatively short duration since market availability ( $<1$ year), cases may not yet be available in the literature.

Overall, no cases of abuse, misuse, dependence, addiction, diversion, or withdrawal syndrome related to fingolimod were identified. A single case of deliberate overdose was identified. The subject had a history of depression and had ingested a non-CNS medication in addition to fingolimod (28 fingolimod $5 \mathrm{mg}$ tablets in addition to 4 phenoxymethylpenicillin $500 \mathrm{mg}$ tablets). Although there is no indication that the case was related to abuse of fingolimod, it has been included for completeness, as it was not clearly stated as an attempted suicide or other self-harm attempt (Stephenson et al. 2014).

In addition, the FDA review documents for siponimod (Center for Drug Evaluation and Research (CDER), 2019b) indicate that "The Sponsor conducted searches for reports of abuse-related signals with fingolimod (Gilenya ${ }^{\circledR}$ ) using publicly available post-marketing sources, including World Health Organization (WHO) VigiBase, FDA Adverse Event Reporting System (FAERS), National Poison Data System (NPDS), Drug Abuse Warning Network (DAWN, for the year 2011), scientific literature (Pubmed, up to January 2018), and Internet forums (Erowid Experience Vaults, Bluelight, and Drug Form; up to January 2018). Most searches covered a period of up to February 2017, no signals of abuse, misuse, diversion, dependence or withdrawal with fingolimod were identified." Several cases of potential rebound or relapse of MS symptoms following discontinuation of fingolimod (Alroughani et al. 2014; AlvarezGonzalez et al. 2017; Beran et al. 2013; Berger et al. 2015; Czlonkowska et al. 2017; Davion et al. 2016; Faissner et al. 2015; Forci et al. 2017; Fragoso et al. 2019; Ghezzi et al. 2013; Giordana et al. 2018; Gunduz et al. 2017; Hakiki et al. 2012; Havla et al. 2012; La Mantia et al. 2014; Lapierre et al. 2016; Lapucci et al. 2019; Novi et al. 2017; Sacco et al. 2020; Sanchez et al. 2018; Sempere et al. 2013; Ward et al. 2016) and one potential case from a clinical trial involving siponimod (Litwin et al. 2018) were reported. In the latter case, disease exacerbation was reported 12 weeks after siponimod discontinuation. Recurrence of disease activity within 10 to 12 weeks of discontinuing effective MS DMT therapy is not unexpected in MS. A few non-clinical studies have identified a potential mechanism of relapse/rebound with fingolimod as being related to lymphocyte re-infiltration (Reddy et al. 2014; Yoshida et al. 2011), an effect that is observed with other immunosuppressive agents such as natalizumab. Indeed, none of the case reports referenced above contained any mention of withdrawal symptoms, other than the recurrence of the disease. In addition, the presence 
Table 5 Incidence (\%) of CNS adverse events of potential interest with ponesimod from the double-blind part of the Phase 3 study in MS patients from review documents

\begin{tabular}{|c|c|c|}
\hline Adverse event term & $\begin{array}{l}\text { Percent incidence with ponesimod } \\
20 \mathrm{mg} \\
N=565\end{array}$ & $\begin{array}{l}\text { Percent incidence } \\
\text { with teriflunomide } \\
14 \mathrm{mg} \mathrm{N}=566\end{array}$ \\
\hline Depression & 3.7 & 5.1 \\
\hline Anxiety & 3.2 & 2.8 \\
\hline Somnolence & 3.2 & 1.6 \\
\hline Cognitive disorder & 0.7 & 0 \\
\hline Disturbance in attention & 0.5 & 0.5 \\
\hline Depressed mood & 0.5 & 0.9 \\
\hline Depressive disorder & 0.4 & 0 \\
\hline Memory impairment & 0.4 & 0.2 \\
\hline Sensory disturbance & 0.4 & 0.7 \\
\hline Drug withdrawal syndrome & 0.2 & 0 \\
\hline Energy increased & 0.2 & 0 \\
\hline Feeling abnormal & 0.2 & 0.4 \\
\hline Hallucination auditory & 0.2 & 0 \\
\hline Suicidal ideation & 0.2 & 0 \\
\hline Amnesia & 0 & 0.2 \\
\hline Lethargy & 0 & 0.4 \\
\hline Affect lability & 0 & 0.7 \\
\hline Agitation & 0 & 0.2 \\
\hline Confusional state & 0 & 0.2 \\
\hline Derealization & 0 & 0.2 \\
\hline Disorientation & 0 & 0.2 \\
\hline Irritability & 0 & 0.2 \\
\hline Restlessness & 0 & 0.2 \\
\hline
\end{tabular}

Modified from CDER 2021

The values presented in this table are the incidence (\%) of adverse events with ponesimod or teriflunomide-incidence (\%) of adverse events with placebo

CNS central nervous system; $M S$ multiple sclerosis of a rebound effect vs. simply a relapse of the disease following fingolimod discontinuation has not been confirmed beyond individual case reports and several small retrospective chart reviews, in which rebound was suspected in 5\% to $10 \%$ of the patients who discontinued fingolimod but causality cannot be confirmed (Evangelopoulos et al. 2018; Frau et al. 2018). Large retrospective analyses investigating more than 2000 patients from clinical trials of fingolimod failed to find a difference with regard to exceptionally high disease activity between previously placebo- and fingolimod-treated patients after study drug discontinuation (De-Vera et al. 2010; Vermersch et al. 2017; Vollmer et al. 2013), although the US prescribing information for fingolimod now contains a warning regarding the potential for severe increase in disability after stopping (Gilenya Prescribing Information, 2018).

Although this immunologic phenomenon has no relevance to the dependence potential of fingolimod (i.e., emergence of withdrawal symptoms, which may lead to the continued use of a drug beyond the time that it is medically indicated), it is nonetheless important from a clinical management perspective that any discontinuation of DMTs should be accompanied by careful monitoring for relapse or potential rebound effects.

Overall, no cases of fingolimod abuse, misuse, addiction, dependence, diversion, or withdrawal syndrome were identified in the scientific literature. Furthermore, there is no evidence that fingolimod has any other abuse-related subjective effects or potential for psychological dependence, which would be necessary components of any potential dependence syndrome.

\section{Discussion and conclusions}

Prescription drug abuse is a major public health problem in the USA and other countries. A few studies have found a higher incidence of substance use disorders in MS patients compared with the general population, which may be associated with risk-taking behavior as a predisposing factor to the development of MS rather than substance use after the onset of MS (e.g., higher risk of pre-symptomatic use of alcohol and recreational drugs) (Bombardier et al. 2004; 
Hawkes and Boniface 2014). Given the possibility of abuse of CNS-active drugs, even those that are not controlled, it is important to review the information for the new drugs, even those for relatively small and objectively diagnosed populations, such as MS patients, who may present unique risk factors. The available literature and public documents indicate that $\mathrm{S} 1 \mathrm{P}$ receptor modulators, such as ponesimod, ozanimod, siponimod, fingolimod, and those in development, are not likely to be abused. Although it is possible that the lack of reports of actual abuse or misuse of fingolimod, which has been marketed for more than 10 years, are related to under-reporting due to a lack of awareness of the issue, the limited non-clinical data and extensive AE reports suggest that this class does not have properties that would make them attractive for abuse, such as mood-elevating, sedative, stimulant, or hallucinogenic effects. One limitation of the AE data obtained from the literature is that many articles only presented more common AEs, typically those occurring in $>5 \%$ or $10 \%$ of the patients; therefore, less frequently observed CNS AEs may not have been reported. Although it is suggested that some AEs of potential interest for abuse may not have been reported, the fact that these AEs are not common enough to be reported at the $5 \%$ or $10 \%$ threshold lends credence to the idea that these drugs do not produce CNS effects frequently enough to be of interest to abusers. This was confirmed in the FDA review documents for ponesimod, fingolimod, siponimod, and ozanimod, in which CNS AEs were reported relatively infrequently, the most common of which were dizziness and possibly insomnia, along with other neuropsychiatric AEs, such as anxiety, depression, or fatigue/asthenia, which are not directly related to abuse potential. While ponesimod was associated with cases of "euphoric mood" in phase 1 studies in healthy subjects that were apparently not seen with other members of this class, it is unclear whether this will be associated with abuse in the post-market setting. Notably, some of the phase 1 studies in question were open-label, and therefore the data are difficult to interpret in the absence of a placebo control. In addition, this class of drugs is associated with events that may be aversive and further deter any potential for experimentation, such as headache, diarrhea, liver transaminase elevation, cough, influenza, sinusitis, and pain (Vollmer et al. 2013).

Finally, this review was based on public literature and data sources and does not comprehensively review all potential data sources for the identification of potential abuse signals, such as FAERS and EudraVigilance or other postmarketing surveillance systems. Such evaluations would be beyond the scope of this review. In addition, to our knowledge, no human abuse potential study considered as the gold standard for evaluating the potential for recreational abuse of a drug has been conducted with a member of this class and no systematic evaluation of physical dependence in humans is available. Although no data suggest that S1P receptor modulators are associated with a withdrawal syndrome similar to other DMTs, a potential for recurrence of the disease exists, and although unproven, rebound activity should be considered.

Despite the limitations of the available data, S1P receptor modulators, such as fingolimod, siponimod, ponesimod, and ozanimod, as well as similar drugs in development, assuming that they show selectivity for S1P receptors, do not appear to be associated with abuse or dependence potential, and no signals of abuse or dependence were identified in the literature or other public documents.

Acknowledgements The authors gratefully acknowledge Sivaram Vedantam and Jitendriya Mishra for providing editorial support, which encompassed a literature search, manuscript revision, and submission, all under the direction of the authors and Anuja Shah for editorial review support. Funding for the editorial support was provided by Novartis Pharma AG.

Author contribution All authors contributed to the writing, review, and approval of the manuscript.

\section{Declarations}

Conflict of interest The authors did not receive payment for the preparation of the article; however, Dr. Schoedel provides consulting services to Novartis Pharma AG and other pharmaceutical companies. Dr. Kolly, Dr. Gardin, Mr. Neelakantham, and Dr. Shakeri-Nejad are employees of Novartis.

Open Access This article is licensed under a Creative Commons Attribution 4.0 International License, which permits use, sharing, adaptation, distribution and reproduction in any medium or format, as long as you give appropriate credit to the original author(s) and the source, provide a link to the Creative Commons licence, and indicate if changes were made. The images or other third party material in this article are included in the article's Creative Commons licence, unless indicated otherwise in a credit line to the material. If material is not included in the article's Creative Commons licence and your intended use is not permitted by statutory regulation or exceeds the permitted use, you will need to obtain permission directly from the copyright holder. To view a copy of this licence, visit http://creativecommons.org/licenses/by/4.0/.

\section{References}

Al-Hussain F, Al-Salloum N, Alazwary N, Saeedi J, Howaidi S, Daif A (2017) Depression, anxiety and stress severities in multiple sclerosis patients using injectable versus oral treatments. J Comp Eff Res 6:405-412

Al-Salama ZT (2019) Siponimod: first global approval. Drugs 79:1009-1015

Alroughani R, Almulla A, Lamdhade S, Thussu A (2014) Multiple sclerosis reactivation postfingolimod cessation: is it IRIS? BMJ Case Rep 2014.

Alvarez-Gonzalez C, Adams A, Mathews J, Turner BP, Giovannoni G, Baker D, Schmierer K (2017) Cladribine to treat disease exacerbation after fingolimod discontinuation in progressive multiple sclerosis. Ann Clin Transl Neurol 4:506-511 
Beran RG, Hegazi Y, Schwartz RS, Cordato DJ (2013) Rebound exacerbation multiple sclerosis following cessation of oral treatment. Mult Scler Relat Disord 2:252-255

Berger B, Baumgartner A, Rauer S, Mader I, Luetzen N, Farenkopf U, Stich O (2015) Severe disease reactivation in four patients with relapsing-remitting multiple sclerosis after fingolimod cessation. J Neuroimmunol 282:118-122

Berry JD, Paganoni S, Atassi N, Macklin EA, Goyal N, Rivner M, Simpson E, Appel S, Grasso DL, Mejia NI, Mateen F, Gill A, Vieira F, Tassinari V, Perrin S (2017) Phase IIa trial of fingolimod for amyotrophic lateral sclerosis demonstrates acceptable acute safety and tolerability. Muscle Nerve 56:1077-1084

Biswal S, Polus F, Pal P, Veldandi UK, Marbury TC, Perry R, Legangneux E (2015) Pharmacokinetic and pharmacodynamic interaction of siponimod (BAF312) and propranolol in healthy subjects. Int J Clin Pharmacol Ther 53:855-865

Boehler M, Juif PE, Hoch M, Dingemanse J (2017) Absolute bioavailability of ponesimod, a selective $\mathrm{S}_{1} \mathrm{P}_{1}$ receptor modulator, in healthy male subjects. Eur J Drug Metab Pharmacokinet 42:129-134

Bombardier CH, Blake KD, Ehde DM, Gibbons LE, Moore D, Kraft GH (2004) Alcohol and drug abuse among persons with multiple sclerosis. Mult Scler 10:35-40

Brossard P, Scherz M, Halabi A, Maatouk H, Krause A, Dingemanse J (2014) Multiple-dose tolerability, pharmacokinetics, and pharmacodynamics of ponesimod, an S1P1 receptor modulator: favorable impact of dose up-titration. J Clin Pharmacol 54:179-188

Budde K, Schmouder RL, Brunkhorst R, Nashan B, Lucker PW, Mayer T, Choudhury S, Skerjanec A, Kraus G, Neumayer HH (2002) First human trial of FTY720, a novel immunomodulator, in stable renal transplant patients. J Am Soc Nephrol 13:1073-1083

Calabresi PA, Radue EW, Goodin D, Jeffery D, Rammohan KW, Reder AT, Vollmer T, Agius MA, Kappos L, Stites T, Li B, Cappiello L, von Rosenstiel P, Lublin FD (2014) Safety and efficacy of fingolimod in patients with relapsing-remitting multiple sclerosis (FREEDOMS II): a double-blind, randomised, placebocontrolled, phase 3 trial. Lancet Neurol 13:545-556

Cascione M, Tenenbaum N, Wendt J, Meng X, Schofield L, Cree BAC, investigators $\mathrm{P}$ (2018) Treatment retention on fingolimod compared with injectable multiple sclerosis therapies in AfricanAmerican patients: a subgroup analysis of a randomized phase 4 study. Mult Scler Relat Disord 25:50-56

Center for Drug Evaluation and Research (CDER) (2021) Other Review(s): Ponvory (ponesimod). https://www.accessdata.fda. gov/drugsatfda_docs/nda/2021/213498Orig 1s000OtherR.pdf. Accessed 16 Jun 2021

Center for Drug Evaluation and Research (CDER) (2020a) Summary review: Zeposia (ozanimod). https://www.accessdata.fda. gov/drugsatfda_docs/nda/2020/209899Orig 1s000SumR.pdf. Accessed 16 Jun 2021

Center for Drug Evaluation and Research (CDER) (2020b) Drug approval package: Zeposia (ozanimod) "Other Reviews". https:// www.accessdata.fda.gov/drugsatfda_docs/nda/2020/209899Orig 1s000TOC.cfm. Accessed 16 Jun 2020.

Center for Drug Evaluation and Research (CDER) (2020c) Clinical pharmacology review(s): Ponvory (ponesimod). https://www. accessdata.fda.gov/drugsatfda_docs/nda/2021/2134980rig1s000 ClinPharmR.pdf. Accessed 16 Jun 2021.

Center for Drug Evaluation and Research (CDER) (2019a) Draft guidance for industry - drug abuse and dependence section of labeling for human prescription drug and biological products - content and format guidance for industry. https://www.fda.gov/regul atory-information/search-fda-guidance-documents/drug-abuseand-dependence-section-labeling-human-prescription-drug-andbiological-products-content. Accessed 16 Jun 2020.
Center for Drug Evaluation and Research (CDER) (2019b) Drug approval package: Mayzent (siponimod) "Other Reviews", https://www.accessdata.fda.gov/drugsatfda_docs/nda/2019/ 209884Orig1s000TOC.cfm, Accessed 16 Jun 2020.

Center for Drug Evaluation and Research (CDER) (2017) Guidance for industry - assessment of abuse potential of drugs. https://www. fda.gov/regulatory-information/search-fda-guidance-documents/ assessment-abuse-potential-drugs. Accessed 16 Jun 2020

Center for Drug Evaluation and Research (CDER) (2010a) Gilenya clinical pharmacology and biopharmaceutics review(s). https:// www.accessdata.fda.gov/drugsatfda_docs/nda/2010/022527Orig 1s000clinpharmr.pdf.

Center for Drug Evaluation and Research (CDER) (2010b) Drug approval package: Gilenya (fingolimod): other review(s), Available at: https://www.accessdata.fda.gov/drugsatfda docs/nda/2010/022527Orig1s000otherr.pdf. (Assessed on 16 Jun 2020).

Chaudhry BZ, Cohen JA, Conway DS (2017) Sphingosine 1-phosphate receptor modulators for the treatment of multiple sclerosis. Neurotherapeutics 14:859-873

Cohen JA, Arnold DL, Comi G, Bar-Or A, Gujrathi S, Hartung JP, Cravets M, Olson A, Frohna PA, Selmaj KW, Group RS (2016) Safety and efficacy of the selective sphingosine 1-phosphate receptor modulator ozanimod in relapsing multiple sclerosis (RADIANCE): a randomised, placebo-controlled, phase 2 trial. Lancet Neurol 15:373-381

Czlonkowska A, Smolinski L, Litwin T (2017) Severe disease exacerbations in patients with multiple sclerosis after discontinuing fingolimod. Neurol Neurochir Pol 51:156-162

David OJ, Kovarik JM, Schmouder RL (2012) Clinical pharmacokinetics of fingolimod. Clin Pharmacokinet 51:15-28

Davion JB, Cambron M, Duhin E, Chouraki A, Lacour A, Labauge P, Carra C, Ayrignac X, Vermersch P (2016) Two cases of relapses in primary progressive multiple sclerosis after fingolimod withdrawal. J Neurol 263:1361-1363

De-Vera A, Kappos L, Zhang-Auberson L, et al. (2010) Pooled efficacy data demonstrate that fingolimod reduces multiple sclerosis relapse rate with no evidence of rebound after discontinuing treatment. Presented at 26th Congress of the European Committee for Treatment and Research in Multiple Sclerosis (ECTRIMS) 13-16 October 2010, Gothenburg, Sweden. Poster no. P844

Evangelopoulos ME, Miclea A, Schrewe L, Briner M, Salmen A, Engelhardt B, Huwiler A, Chan A, Hoepner R (2018) Frequency and clinical characteristics of multiple sclerosis rebounds after withdrawal of Fingolimod. CNS Neurosci Ther 24:984-986

Evoy KE, Covvey JR, Peckham AM, Ochs L, Hultgren KE (2019) Reports of gabapentin and pregabalin abuse, misuse, dependence, or overdose: an analysis of the Food and Drug Administration Adverse Events Reporting System (FAERS). Res Social Adm Pharm 15:953-958

Faissner S, Hoepner R, Lukas C, Chan A, Gold R, Ellrichmann G (2015) Tumefactive multiple sclerosis lesions in two patients after cessation of fingolimod treatment. Ther Adv Neurol Disord 8:233-238

Forci B, Mariottini A, Mechi C, Massacesi L, Repice A (2017) Disease reactivation following fingolimod withdrawal in multiple sclerosis: two case reports. Mult Scler Relat Disord 15:24-26

Fox E, Edwards K, Burch G et al (2014) Outcomes of switching directly to oral fingolimod from injectable therapies: Results of the randomized, open-label, multicenter, Evaluate Patient OutComes (EPOC) study in relapsing multiple sclerosis. Mult Scler Relat Disord 3(5):607-619

Fragoso YD, Adoni T, Gomes S, Goncalves MVM, Parolin LF, Rosa G, Ruocco HH (2019) Severe exacerbation of multiple sclerosis following withdrawal of fingolimod. Clin Drug Investig 39:909-913 
Frau J, Sormani MP, Signori A, Realmuto S, Baroncini D, Annovazzi P, Signoriello E, Maniscalco GT, La Gioia S, Cordioli C, Frigeni B, Rasia S, Fenu G, Grasso R, Sartori A, Lanzillo R, Stromillo ML, Rossi S, Forci B, Cocco E, i-Mu STsg, (2018) Clinical activity after fingolimod cessation: disease reactivation or rebound? Eur J Neurol 25:1270-1275

Gardin A, Dodman A, Kalluri S, Neelakantham S, Tan X, Legangneux E, Shakeri-Nejad K (2017) Pharmacokinetics, safety, and tolerability of siponimod (BAF312) in subjects with severe renal impairment: a single-dose, open-label, parallel-group study. Int J Clin Pharmacol Ther 55:54-65

Gardin A, Gray C, Neelakantham S, Huth F, Davidson AM, Dumitras S, Legangneux E, Shakeri-Nejad K (2018) Siponimod pharmacokinetics, safety, and tolerability in combination with rifampin, a CYP2C9/3A4 inducer, in healthy subjects. Eur J Clin Pharmacol 74:1593-1604

Gasim M, Bernstein CN, Graff LA, Patten SB, El-Gabalawy R, Sareen J, Bolton JM, Marriott JJ, Fisk JD, Marrie RA et al (2018) Adverse psychiatric effects of disease-modifying therapies in multiple Sclerosis: a systematic review. Mult Scler Relat Disord 26:124-156

Gentile A, Musella A, Bullitta S, Fresegna D, De Vito F, Fantozzi R, Piras E, Gargano F, Borsellino G, Battistini L, Schubart A, Mandolesi G, Centonze D (2016) Siponimod (BAF312) prevents synaptic neurodegeneration in experimental multiple sclerosis. J Neuroinflammation 13:207

Gergely P, Nuesslein-Hildesheim B, Guerini D, Brinkmann V, Traebert M, Bruns C, Pan S, Gray NS, Hinterding K, Cooke NG, Groenewegen A, Vitaliti A, Sing T, Luttringer O, Yang J, Gardin A, Wang N, Crumb WJ Jr, Saltzman M, Rosenberg M, Wallstrom E (2012) The selective sphingosine 1-phosphate receptor modulator BAF312 redirects lymphocyte distribution and has speciesspecific effects on heart rate. Br J Pharmacol 167:1035-1047

Ghezzi A, Rocca MA, Baroncini D, Annovazzi P, Zaffaroni M, Minonzio G, Comi G, Filippi M (2013) Disease reactivation after fingolimod discontinuation in two multiple sclerosis patients. J Neurol 260:327-329

Gilenya ${ }^{\circledR}$ (fingolimod) tablets [highlights of prescribing information]. East Hanover, NJ, USA: Novartis Pharmaceuticals Corporation; 2018.

Giordana MT, Cavalla P, Uccelli A, Laroni A, Bandini F, Vercellino M, Mancardi G (2018) Overexpression of sphingosine-1-phosphate receptors on reactive astrocytes drives neuropathology of multiple sclerosis rebound after fingolimod discontinuation. Mult Scler 24:1133-1137

Glaenzel U, Jin Y, Nufer R, Li W, Schroer K, Adam-Stitah S, Peter van Marle S, Legangneux E, Borell H, James AD, Meissner A, Camenisch G, Gardin A (2018) Metabolism and disposition of siponimod, a novel selective S1P1/S1P5 agonist, in healthy volunteers and in vitro identification of human cytochrome P450 enzymes involved in its oxidative metabolism. Drug Metab Dispos 46:1001-1013

Guerard N, Zwingelstein C, Hoch M, Dingemanse J (2016) Effect of hepatic or renal impairment on the pharmacokinetics, safety, and tolerability of ponesimod, a selective S1P1 receptor modulator. Basic Clin Pharmacol Toxicol 118:356-368

Gunduz T, Kurtuncu M, Eraksoy M (2017) Severe rebound after withdrawal of fingolimod treatment in patients with multiple sclerosis. Mult Scler Relat Disord 11:1-3

Hakiki B, Portaccio E, Giannini M, Razzolini L, Pasto L, Amato MP (2012) Withdrawal of fingolimod treatment for relapsingremitting multiple sclerosis: report of six cases. Mult Scler 18:1636-1639

Havla JB, Pellkofer HL, Meinl I, Gerdes LA, Hohlfeld R, Kumpfel T (2012) Rebound of disease activity after withdrawal of fingolimod (FTY720) treatment. Arch Neurol 69:262-264
Hawkes CH, Boniface D (2014) Risk associated behavior in premorbid multiple sclerosis: a case-control study. Mult Scler Relat Disord 3:40-47

Hoch M, D'Ambrosio D, Wilbraham D, Brossard P, Dingemanse J (2014) Clinical pharmacology of ponesimod, a selective S1P(1) receptor modulator, after uptitration to supratherapeutic doses in healthy subjects. Eur J Pharm Sci 63:147-153

Hoch M, Darpo B, Brossard P, Zhou M, Stoltz R, Dingemanse J (2015) Effect of ponesimod, a selective S1P1 receptor modulator, on the QT interval in healthy individuals. Basic Clin Pharmacol Toxicol 116:429-437

Hughes R, Dalakas MC, Merkies I, Latov N, Leger JM, NobileOrazio E, Sobue G, Genge A, Cornblath D, Merschhemke M, Ervin CM, Agoropoulou C, Hartung HP, Investigators FT (2018) Oral fingolimod for chronic inflammatory demyelinating polyradiculoneuropathy (FORCIDP Trial): a doubleblind, multicentre, randomised controlled trial. Lancet Neurol 17:689-698

Juif PE, Hoch M, D’Ambrosio D, Dingemanse J (2015) Biocomparison of three formulations of the S1P1 receptor modulator ponesimod in healthy subjects. Drugs R D 15:203-210

Juif PE, Hoch M, Vaclavkova A, Krause A, Bush J, Dingemanse J (2017) Mitigation of initial cardiodynamic effects of the S1P1 receptor modulator ponesimod using a novel up-titration regimen. J Clin Pharmacol 57:401-410

Kanno T, Nishizaki T (2011) Endogenous sphingosine 1-phosphate regulates spontaneous glutamate release from mossy fiber terminals via S1P(3) receptors. Life Sci 89:137-140

Kappos L, Antel J, Comi G, Montalban X, O'Connor P, Polman CH, Haas T, Korn AA, Karlsson G, Radue EW, Group FDS (2006) Oral fingolimod (FTY720) for relapsing multiple sclerosis. N Engl J Med 355:1124-1140

Kappos L, Bar-Or A, Cree BAC, Fox RJ, Giovannoni G, Gold R, Vermersch P, Arnold DL, Arnould S, Scherz T, Wolf C, Wallstrom E, Dahlke F, Investigators EC (2018) Siponimod versus placebo in secondary progressive multiple sclerosis (EXPAND): a double-blind, randomised, phase 3 study. Lancet 391:1263-1273

Kappos L, Radue EW, O'Connor P, Polman C, Hohlfeld R, Calabresi P, Selmaj K, Agoropoulou C, Leyk M, Zhang-Auberson L, Burtin P, Group FS (2010) A placebo-controlled trial of oral fingolimod in relapsing multiple sclerosis. N Engl J Med 362:387-401

Khatri B, Barkhof F, Comi G, Hartung HP, Kappos L, Montalban X, Pelletier J, Stites T, Wu S, Holdbrook F, Zhang-Auberson L, Francis G, Cohen JA, Group TS (2011) Comparison of fingolimod with interferon beta-1a in relapsing-remitting multiple sclerosis: a randomised extension of the TRANSFORMS study. Lancet Neurol 10:520-529

La Mantia L, Prone V, Marazzi MR, Erminio C, Protti A (2014) Multiple sclerosis rebound after fingolimod discontinuation for lymphopenia. Neurol Sci 35:1485-1486

Landi D, Vollaro S, Pellegrino G, Mulas D, Ghazaryan A, Falato E, Pasqualetti P, Rossini PM, Filippi MM (2015) Oral fingolimod reduces glutamate-mediated intracortical excitability in relapsing-remitting multiple sclerosis. Clin Neurophysiol 126:165-169

Lapierre Y, O'Connor P, Devonshire V, Freedman MS, Kremenchutzky M, Yeung M, Schecter R (2016) Canadian experience with fingolimod: adherence to treatment and monitoring. Can J Neurol Sci 43:278-283

Lapucci C, Baroncini D, Cellerino M, Boffa G, Callegari I, Pardini M, Novi G, Sormani MP, Mancardi GL, Ghezzi A, Zaffaroni M, Uccelli A, Inglese M, Roccatagliata L (2019) Different MRI patterns in MS worsening after stopping fingolimod. Neurol Neuroimmunol Neuroinflamm 6:e566

Laroni A, Brogi D, Morra VB, Guidi L, Pozzilli C, Comi G, Lugaresi A, Turrini R, Raimondi D, Uccelli A, Mancardi GL, Investigators EAP (2014) Safety of the first dose of fingolimod for multiple 
sclerosis: results of an open-label clinical trial. BMC Neurol $14: 65$

Lin JH (2008) CSF as a surrogate for assessing CNS exposure: an industrial perspective. Curr Drug Metab 9:46-59

Litwin T, Smolinski L, Czlonkowka A (2018) Substantial disease exacerbation in a patient with relapsing-remitting multiple sclerosis after withdrawal from siponimod. Neurol Neurochir Pol 52:98-101

Lublin F, Miller DH, Freedman MS, Cree BAC, Wolinsky JS, Weiner H, Lubetzki C, Hartung HP, Montalban X, Uitdehaag BMJ, Merschhemke M, Li B, Putzki N, Liu FC, Haring DA, Kappos L, investigators Is (2016) Oral fingolimod in primary progressive multiple sclerosis (INFORMS): a phase 3, randomised, doubleblind, placebo-controlled trial. Lancet 387:1075-1084

Mansbach RS, Schoedel KA, Kittrelle JP, Sellers EM (2010) The role of adverse events and related safety data in the pre-market evaluation of drug abuse potential. Drug Alcohol Depend 112:173-177

Marrie RA, Cohen J, Stuve O, Trojano M, Sorensen PS, Reingold S, Cutter G, Reider N (2015) A systematic review of the incidence and prevalence of comorbidity in multiple sclerosis: overview. Mult Scler 21:263-281

MAYZENT® (2019) (siponimod) tablets [highlights of prescribing information]. East Hanover, NJ, USA: Novartis Pharmaceuticals Corporation

Montalban X, Comi G, Antel J, O'Connor P, de Vera A, Cremer M, Sfikas N, von Rosenstiel P, Kappos L (2015) Long-term results from a phase 2 extension study of fingolimod at high and approved dose in relapsing multiple sclerosis. J Neurol 262:2627-2634

Moreau T, Bungener C, Heinzlef O, Suchet L, Borgel F, Bourdeix I, Meite M, Rerat K, Chouette I, Group GS (2017) Anxiety and coping strategy changes in multiple sclerosis patients initiating fingolimod: the GRACE prospective study. Eur Neurol 77:47-55

Newcombe J, Uddin A, Dove R, Patel B, Turski L, Nishizawa Y, Smith T (2008) Glutamate receptor expression in multiple sclerosis lesions. Brain Pathol 18:52-61

Novi G, Ghezzi A, Pizzorno M, Lapucci C, Bandini F, Annovazzi P, Mancardi GL, Uccelli A (2017) Dramatic rebounds of MS during pregnancy following fingolimod withdrawal. Neurol Neuroimmunol Neuroinflamm 4:e377

Olsson T, Boster A, Fernandez O, Freedman MS, Pozzilli C, Bach D, Berkani O, Mueller MS, Sidorenko T, Radue EW, Melanson M (2014) Oral ponesimod in relapsing-remitting multiple sclerosis: a randomised phase II trial. J Neurol Neurosurg Psychiatry 85:1198-1208

Ordonez-Boschetti L, Rey R, Cruz A, Sinha A, Reynolds T, Frider N, Alvarenga R (2015) Safety and tolerability of fingolimod in latin American Patients with relapsing-remitting multiple sclerosis: the open-label FIRST LATAM study. Adv Ther 32:626-635

Ponvory ${ }^{\mathrm{TM}}$ (ponesimod) tablets [Highlights of Prescribing Information]. Janssen Pharmaceuticals Inc,. Titusville, NJ, US. 2021

Rasche L, Paul F (2018) Ozanimod for the treatment of relapsing remitting multiple sclerosis. Expert Opin Pharmacother 19:2073-2086

Reddy PB, Sehrawat S, Suryawanshi A, Rajasagi NK, Khatri M, Rouse BT (2014) An approach to control relapse of inflammatory lesions after discontinuation of primary therapy. PLoS One 9:e98051

Riganti L, Antonucci F, Gabrielli M, Prada I, Giussani P, Viani P, Valtorta F, Menna E, Matteoli M, Verderio C (2016) Sphingosine1-phosphate (S1P) impacts presynaptic functions by regulating synapsin I localization in the presynaptic compartment. J Neurosci 36:4624-4634

Rojas JI, Patrucco L, Miguez J, Cristiano E (2017) Real-world safety and patient profile of fingolimod in relapsing-remitting multiple sclerosis: a prospective analysis in Buenos Aires, Argentina. Clin Neuropharmacol 40:251-254
Sacco R, Emming S, Gobbi C, Zecca C, Monticelli S (2020) Rebound of disease activity after fingolimod withdrawal: immunological and gene expression profiling. Mult Scler Relat Disord 40:101927

Saida T, Kikuchi S, Itoyama Y, Hao Q, Kurosawa T, Nagato K, Tang D, Zhang-Auberson L, Kira J (2012) A randomized, controlled trial of fingolimod (FTY720) in Japanese patients with multiple sclerosis. Mult Scler 18:1269-1277

Sanchez P, Meca-Lallana V, Vivancos J (2018) Tumefactive multiple sclerosis lesions associated with fingolimod treatment: report of 5 cases. Mult Scler Relat Disord 25:95-98

Scherz MW, Brossard P, D'Ambrosio D, Ipek M, Dingemanse J (2015) Three different up-titration regimens of ponesimod, an S1P1 receptor modulator, in healthy subjects. J Clin Pharmacol 55:688-697

Sellers EM, Romach MK (2018) Categorization of abuse potential-related adverse events. Clin Pharmacol Drug Dev 7:569-574

Selmaj K, Li DK, Hartung HP, Hemmer B, Kappos L, Freedman MS, Stuve O, Rieckmann P, Montalban X, Ziemssen T, Auberson LZ, Pohlmann H, Mercier F, Dahlke F, Wallstrom E (2013) Siponimod for patients with relapsing-remitting multiple sclerosis (BOLD): an adaptive, dose-ranging, randomised, phase 2 study. Lancet Neurol $12: 756-767$

Sempere AP, Berenguer-Ruiz L, Feliu-Rey E (2013) Rebound of disease activity during pregnancy after withdrawal of fingolimod. Eur $\mathbf{J}$ Neurol 20:e109-e110

Shakeri-Nejad K, Aslanis V, Veldandi UK, Mooney L, Pezous N, Brendani B, Juan A, Allison M, Perry R, Legangneux E (2015) Effects of therapeutic and supratherapeutic doses of siponimod (BAF312) on cardiac repolarization in healthy subjects. Clin Ther 37:2489-2505 e2

Sim-Selley LJ, Goforth PB, Mba MU, Macdonald TL, Lynch KR, Milstien S, Spiegel S, Satin LS, Welch SP, Selley DE (2009) Sphingosine-1-phosphate receptors mediate neuromodulatory functions in the CNS. J Neurochem 110:1191-1202

Srinivasan R, Sailasuta N, Hurd R, Nelson S, Pelletier D (2005) Evidence of elevated glutamate in multiple sclerosis using magnetic resonance spectroscopy at $3 \mathrm{~T}$. Brain 128:1016-1025

Stephenson M, Wong A, Rotella JA, Crump N, Kerr F, Greene SL (2014) Deliberate fingolimod overdose presenting with delayed hypotension and bradycardia responsive to atropine. J Med Toxicol 10:215-218

Tauil CB, Grippe TC, Dias RM, Dias-Carneiro RPC, Carneiro NM, Aguilar ACR, Silva FMD, Bezerra F, Almeida LK, Massarente VL, Giovannelli EC, Tilbery CP, Brandao CO, Santos LMB, Santos-Neto LD (2018) Suicidal ideation, anxiety, and depression in patients with multiple sclerosis. Arq Neuropsiquiatr 76:296-301

Tran JQ, Hartung JP, Tompkins CA, Frohna PA (2018) Effects of highand low-fat meals on the pharmacokinetics of ozanimod, a novel sphingosine-1-phosphate receptor modulator. Clin Pharmacol Drug Dev 7:634-640

Tran JQ, Zhang P, Ghosh A, Liu L, Syto M, Wang X, Palmisano M (2020) Single-dose pharmacokinetics of ozanimod and its major active metabolites alone and in combination with gemfibrozil, itraconazole, or rifampin in healthy subjects: a randomized, parallelgroup, open-label study. Adv Ther 37(10):4381-4395

Urbano M, Guerrero M, Rosen H, Roberts E (2013) Modulators of the sphingosine 1-phosphate receptor 1. Bioorg Med Chem Lett 23:6377-6389

Vaclavkova A, Chimenti S, Arenberger P, Hollo P, Sator PG, Burcklen M, Stefani M, D'Ambrosio D (2014) Oral ponesimod in patients with chronic plaque psoriasis: a randomised, double-blind, placebocontrolled phase 2 trial. Lancet 384:2036-2045

Vermersch P, Radue EW, Putzki N, Ritter S, Merschhemke M, Freedman MS (2017) A comparison of multiple sclerosis disease activity after discontinuation of fingolimod and placebo. Mult Scler J Exp Transl Clin 3:2055217317730096 
Vollmer T, Radue E, Vermersch P, et al. (2013) Clinical and magnetic resonance imaging disease activity after fingolimod discontinuation. Presented at 29th Congress of the European Committee for Treatment and Research in Multiple Sclerosis (ECTRIMS) 2-5 October 2013, Copenhagen, Denmark.

Ward MD, Jones DE, Goldman MD (2016) Cryptococcal meningitis after fingolimod discontinuation in a patient with multiple sclerosis. Mult Scler Relat Disord 9:47-49

Yoshida Y, Tsuji T, Fujita T, Kohno T (2011) Relapse of experimental autoimmune encephalomyelitis after discontinuation of FTY720
(Fingolimod) treatment, but not after combination of FTY720 and pathogenic autoantigen. Biol Pharm Bull 34:933-936

ZEPOSIA® (ozanimod) capsules [Highlights of Prescribing Information]. Celgene Corporation Summit, NJ, US. 2020

Publisher's note Springer Nature remains neutral with regard to jurisdictional claims in published maps and institutional affiliations. 